\title{
Giant osteochondroma lower end of femur- A case report
}

\author{
Dr Santosh S Jeevannavar ${ }^{1}$, Dr Keshav S Shenoy ${ }^{2,}$ Dr Prasanna Baindoor ${ }^{3}$ \\ Dr Chidendra M Shettar ${ }^{4}$ \\ I,(Associate professor, Department of orthopaedics, SDM college of medical sciences and hospital-dharwad, \\ india) \\ ${ }^{2.3}$ (Assistant Professor, Department of orthopaedics, SDM college of medical sciences and hospital-dharwad \\ india \\ ${ }^{4}$ (Professor Department of orthopaedics, SDM college of medical sciences and hospital-dharwad, india)
}

\begin{abstract}
A 15 year old boy presented with à painful non mobile, bony hard swelling of lower end of left femur of 4 years duration. The swelling was present since 4 years with progressive increase in size of the swelling and pain on knee movements since last 1 year.

Clinical examination revealed a bony hard swelling arising from medial aspect of lower end of femur away from the knee joint. The swelling was painful on knee flexion of more than 90 degrees. XRays revealed a giant pedunculated exostosis arising from lower end of femur with a fungating mass at the cartilaginous cap abutting the skin. A diagnosis of giant exostoses lower end femur with possible malignant transformation was made. In view of sudden increase in size of the lesion and associated pain on knee movements, and mechanical obstruction Patient underwent surgical excision of the exostoses. Histopathology revealed no malignant transformation.
\end{abstract}

Keywords - exostoses, cartilage cap, malignant transformation, excision

\section{INTRODUCTION}

Solitary osteochondromas (exostoses) are the most common benign bone disorders encountered. Most are benign in nature and treated with wishful neglect. Pain due to mechanical pressure on surrounding neurovascular structures, or risk of malignant transformation is indications for surgical excision. Sudden increase in size associated with pain is indicators of possible malignant transformation. Treatment with Surgical excision gives consistent results and relief of pain.

\section{CASE REPORT}

History

A 15 year old boy presented with pain and bony swelling overlying left knee joint of 4 years duration. Patient first noticed the swelling around 4 year's back which the parents attribute it to a fall from a bicycle. Initially the swelling was small in size and painless and bony hard in consistency. There was no associated pain or limitation in knee movements. However since last 1 year there was pain and progressive increase in size of the swelling, and associated pain on knee flexion above 90 degrees. There was also difficulty in running as the bony swelling rubbed against the normal knee. There was no associated fever or skin breakdown. Patient had not taken any treatment since noticing the swelling. No history of similar bony swellings was there anywhere else in the body.

\section{Clinical examination}

Clinical examination revealed a 15 year old male, moderately built and nourished, with an oval shaped bony mass arising from the anteromedial aspect of lower end of left femur (Fig-1). Skin over the mass was stretched but intact. On palpation the mass was painfull on deep palpation. The surface of the mass was irregular and bony hard in consistency arising from bone and immobile. The lateral knee joint line could be palpated independently suggestive of a bony swelling arising from lower metaphyseal area of femur. There were no local rise in temperature or abnormal pulsations and the edges of the mass were indistinct. The size of the mass clinically was $10 \mathrm{~cm}$ by $8 \mathrm{~cm}$. Clinically there was no evidence suggestive of neurovascular compression. Range of movements at left knee was painless from 0-90 degrees, However when the patient flexed his knee beyond 90-100 degrees there was pain and stretching of the skin overlying the bony mass. Clinical tests for ligaments and menisci around the knee were normal.

\section{Investigations}

Blood investigations -were within normal limits 
$\mathrm{X}$ rays of left femur with knee joint (Fig-2) revealed a pedunculated bony mass arising from anteromedial aspect of left lower end of femur, the medullary canal of mass was continuous with that of femur. Cartilage cap of the mass was fluffy. Diagnosis was suggestive of osteochondroma lower end of left femur.

A skeletal survey was done to rule out multiple exostoses

In view of sudden increase in size of bony swelling and associated pain, a diagnosis of giant exostoses lower end femur with possible malignant transformation was made.

\section{Treatment}

We decided to treat the patient with surgical excision to confirm the diagnosis, to rule out malignant transformation, to reduce pain and to relieve mechanical symptoms.

\section{Surgical procedure}

The lesion was approached through a anteromedial approach, vastus medialis muscle was bluntly dissected and the bony mass with cartilage cap exposed (Figure 3, 4, 5). The lesion was excised with a cuff of normal periosteum flush with parent bone. The tumor measured $9 \mathrm{~cm} * 5 \mathrm{~cm}$ (Figure 6) with a cartilage cap of $1 \mathrm{~cm}$. Post-operative x rays revealed complete excision of the tumor (Fig-7).

The patient had an uneventful post-operative period. Histopathology confirmed the diagnosis of osteochondroma with no features of malignancy. Patient had relief of pain and mechanical symptoms. At 2 years follow up patient had no pain or recurrence, and had full range of movements at the knee.

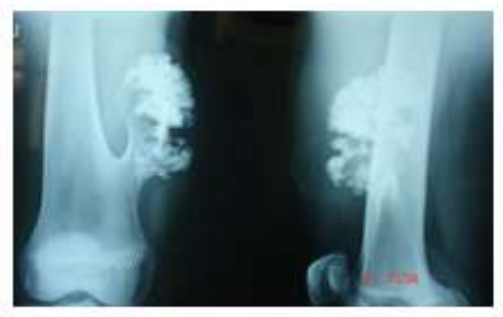

Fig-1

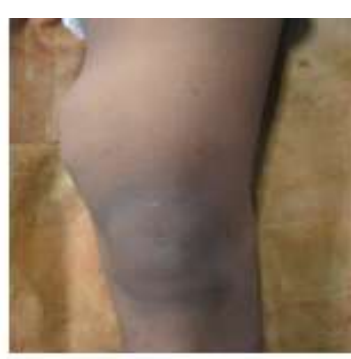

Fig-2

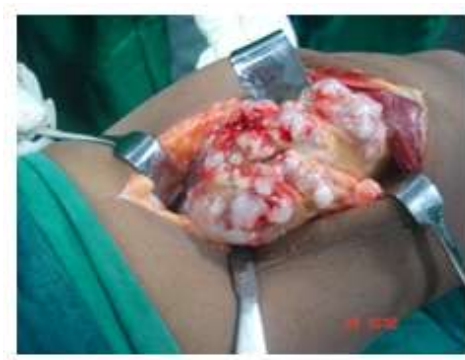

Fig-3

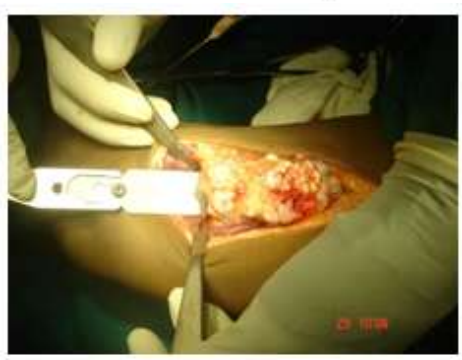

Fig-4

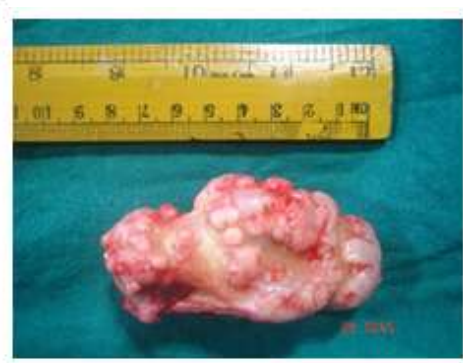

Fig-5

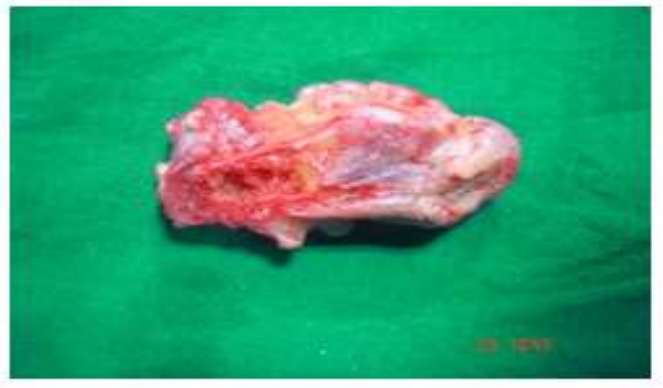

Fig-6

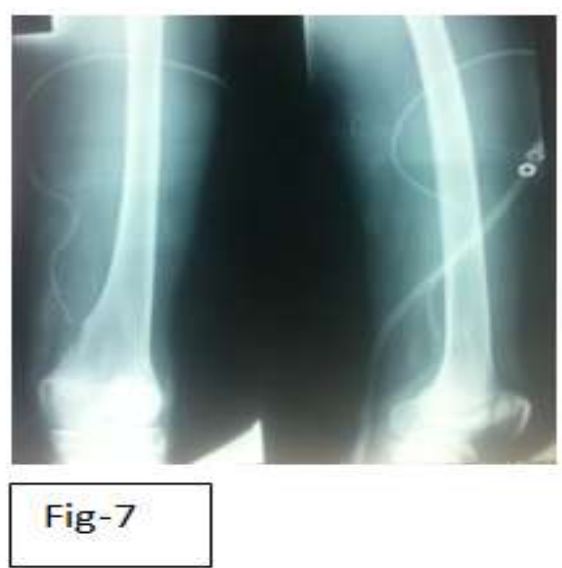




\section{Discussion}

Osteochondroma are most common benign bone tumors encountered. It is considered as a developmental physeal abnormality rather than a primary bone neoplasm. Metaphyseal end of long bones like femur,tibia and humerus are its principal location ${ }^{1,2,3}$. In our case the age group and location was consistent with solitary osteochondroma.. The patient and patient's relatives attributed the painless swelling of 4 years duration to an insignificant fall just before the appearance of the swelling. The gradual and sudden increase in size and associated pain on knee movements over the last year forced the patient to take medical opinion. Several studies have documented the likelihood of malignant transformation if there is sudden increase in size of solitary osteochondroma with associated pain ${ }^{4,5,6}$

Due to the large size of the exostoses, in addition to pain during knee movements there was also associated mechanical obstruction to the other knee when the patient used to run for sporting or other activities. Although most solitary osteochondromas are asymptomatic, pain due to mechanical compression of surrounding neurovascular structures or fracture of the stalk are common symptoms to seek medical attention. In addition to pain, cosmetic deformity is also a major factor to seek opinion and to undergo surgical treatment ${ }^{7,10}$. The main reason for seeking medical opinion in our patient apart from pain was the cosmetic deformity. The XRay appearance was typical of osteochondroma, however the cartilage cap was large and indistinct. Various studies have mentioned about the size of cartilage cap as a predictor for malignancy, with a cartilage cap of more than 2 $\mathrm{cm}$ after skeletal maturity indicative of malignant transformation ${ }^{4,5,8,9,10}$. In our case the presence of pain, limitation of knee movements, cosmetic deformity and the rare possibility of malignant transformation prompted us to perform surgical excision of the tumor. The tumor was excised completely with a cuff of normal periosteum. Patient had complete relief of his symptoms postoperatively. Histopathology confirmed the diagnosis of osteochondroma with no malignant transformation. At two years follow up patient was asymptomatic with complete knee movements.

\section{CONCLUSION}

Giant osteochondromas usually present for cosmetic deformity as well as symptoms produced due to mechanical compression of surrounding structures. Sudden increase in size with associated pain should raise a suspicion of malignant transformation. The size of the cartilage cap should be measured and is a measure of malignant transformation. Surgical excision gives consistent relief of pain and cosmetic deformity, and improves range of motion if restricted.

\section{REFERENCES}

[1] Schajowicz, F: Cartilage-forming tumors. In Tumors and Tumorlike Lesions of Bone.Pathology, Radiology, and Treatment. Ed. 2, pp.141-256. New York, Springer, 1994

[2] Unni, K. K.: Osteochondroma (osteocartilaginous exostosis). In Dahlin's Bone Tumors: GeneralAspects and Data on 11,087 Cases. Ed.5, pp. 11-23. Philadelphia, Lippincott-Raven, 1996.

[3] Canale \& beaty : Campbell"s operative orthopaedics $11^{\text {th }}$ edition. Copyright 2007 mosby an imprint of Elsevier

[4] Bone and soft tissue pathology (pg331-335) -andrew 1.folpe, carrie y .inwards-a volume in the series FOUNDATIONS IN DIAGNOSTIC PATHOLOGY, copyright 2010 by saunders an imprint of Elsevier,inc

[5] Canella P, Gardini F, Boriani S. Exostosis: development, evolution and relationship to malignant degeneration. Ital J Orthop Traumatol1981;7:293-8.

[6] Porter DE, Simpson AHRW. The neoplastic pathogenesis of solitary and multiple osteochondromas. J Pathol 1999; 188:119-25.

[7] Bottner et al., 2003. Bottner F, Rodl R, Kordish I, et al: Surgical treatment of symptomatic osteochondroma: a three- to eight-year follow-up study. J Bone Joint Surg (br) 2003; 85B:1161

[8] Variants of exostosis of the bone in children. -Randy Ray Richardson, MD-Seminars inRoentgenology-Volume 40, Issue 4 , Pages 380-390, October 2005

[9] Malghem J, Vande Berg B, Noel H, et al: Benign osteochondromas and exostotic chondrosarcomas:evaluation of artilage cap thickness by ultrasound. Skeletal Radiol 21:33-37, 1992

[10] Krieg, J. C.; Buckwalter, J. A.; Peterson, K. K.; El-Khoury, G. Y.; and Robinson, R. A.: Extensive growth of an osteochondroma in a skeletally mature patient. A case report. J. Bone and Joint Surg., 77-A: 269-273, Feb. 1995. 